\title{
Modelling the Pattern of Monetary Policy Rates of Ghana
}

\author{
Francis Okyere ${ }^{1}$, Salifu Nanga ${ }^{2}$ \\ ${ }^{1,2}$ (Department of Statistics, School of Graduate Studies, University of Ghana, P. O. Box LG 571, Legon, Accra, \\ Ghana) \\ ${ }^{I}$ (National Vocational Training Institute (NVTI), P. O. Box MB 21, Accra, Ghana) \\ ${ }^{2}$ (Wisconsin International University College, Ghana)
}

\begin{abstract}
The Central Bank monetary policy rate is one of the monetary tools that is use to regulate liquidity in an economy. In Ghana the objectives are to ensure price stability, low inflation and also to support the Government economic objectives including growth and employment. This paper empirically models the monthly monetary policy rates from the year 2001 to 2013 using ARIMA model and the data was obtained from the website of Central Bank of Ghana. From the results, it is reveal that ARIMA $(2,1,1)$ is appropriate for modeling the monetary policy rates of Ghana with a maximum log likelihood value of -133.49 , and least AIC value of 274.98, AICc value of 275.25 and BIC value of 287.16. An ARCH LM test and Ljung-Box test on the residuals of the model revealed that the residuals are free from heteroscedasticity and serial correlation respectively. Hence, it is adequate for forecasting the monetary policy rate of Ghana.
\end{abstract}

Keywords: ARIMA, Central Bank of Ghana, Economy, Forecasting, Monetary policy rate

\section{Introduction}

Many economists have given various definitions of monetary policy. R.P. Kent defines monetary policy as the management of the expansion and contraction of the volume of money in circulation for the explicit purpose of attaining a specific objective such as full employment. Also according to A J. Shapiro, Monetary Policy is the exercise of the central bank's control over the money supply as an instrument for achieving the objectives of economic policy. Again, D.C. Rowan defined monetary policy as discretionary action undertaken by the authorities designed to influence the supply of money, cost of money or rate of interest and the availability of money. Monetary policy is not an end in itself, but a means to an end. It involves the management of money and credit for the furtherance of the general economic policy of the government to achieve the predetermined objectives [14].

There have been varying objectives of monetary policy in different countries in different times and in different economic conditions. Different objectives clash with each other and there is a problem of selecting a right objective for the monetary policy of a country. The proper objective of the monetary policy is to be selected by the monetary authority keeping in view the specific conditions and requirements of the economy [14].

In Ghana, The Bank's monetary policy objective is to ensure price stability, low inflation and subject to that, to support the Government's economic objectives including those for growth and employment. Price stability is defined by the Government's inflation target. This target is revised annually and spelt out clearly in the budget statement for each fiscal year. The object recognizes the role of price stability in achieving economic stability more generally, and in providing the right conditions for sustainable growth in output and employment. The 2002 Bank of Ghana Act made the Bank independent to set interest rates. The Bank is accountable to parliament and the wider public [1].

In February, 2014, Bank of Ghana monetary policy committee (MPC) held an emergency meeting to review recent global and domestic economic developments and assess risks to the outlook. Based on the evaluation, the Committee is of the view that the risks to inflation and exchange rate stability are highly elevated and therefore decided to increase the policy rate by 200 basis points to 18 percent [1]. There is a general assertion that the Bank of Ghana policy rate has a lot of effect on the commercial banks lending rate by way of increasing cost of borrowing.

The Central Bank policy rate is one of the monetary tools that is use to regulate liquidity in an economy. Commercial banks play an intermediary role by borrowing at a rate from the central bank and lending it to individuals and organizations. The public usually had to borrow from the commercial banks to finance projects and programs which they do not have sufficient savings to cover. Notwithstanding the fact that there are other financing options to the public, the primary source of finance in Ghana recently is through bank loans. Such loans come at a cost higher than the price at which the commercial banks borrowed from the central bank. A number of studies have provided evidence that these credit market imperfections may explain differences in behavior of small and large firms during periods of tight credit. For example, small firms appear to account for a larger share of the decline in manufacturing activity and reduced inventory demand that follows a monetary 
tightening [6]. This behavior is consistent with the view that restrictions in the availability of bank credit could have macroeconomic consequences by affecting the investment and spending decisions of bank-dependent borrowers.

For monetary policy to operate through a credit channel, not only must there be bank dependent borrowers but monetary policy must also directly affect banks willingness to lend. To determine whether monetary policy affects bank lending, some studies have examined how banks adjust their portfolios in periods of monetary tightening, while other studies have looked at changes in the price and non-price terms of lending [2][5].

Gertler and Gilchrist conducted a study that specifically looked at how bank business lending responds to policy tightening. Their study reveals that business lending does not decline when policy is tightened. They concluded that the entire decline in total lending comes from a reduction in consumer and real estate loans. Moreover, they added, when the analysis is narrowed further to loans to manufacturing firms, bank lending actually shows a significant increase in response to tighter policy. Indeed, for manufacturing firms, most of the increased lending appears to go to large firms; while loans to small manufacturing firms are largely unaffected by policy tightening. Thus, there is little evidence banks actually reduce lending to small firms when monetary policy is tightened [5].

In contrast to Gertler and Gilchrist study, Kashyap and Stein find evidence that business lending may respond to a tightening of monetary policy. They examine the lending behavior of small and large banks, rather than loans received by small and large firms. They find that when policy is tightened, both total loans and business loans at small banks fall, while loans at large banks are unaffected. The differential response of small banks may indicate they have less access to alternative funding sources than large banks and so are less able to avoid the loss of core deposits when policy is tightened. Since small banks lend primarily to smaller firms, their finding is consistent with the view that monetary policy may work, in part, through a credit channel [11].

Kashyap and Stein note that the lending is a statement about the relative magnitude of shifts in the demand for and supply of loans when policy is tightened. According to the lending view, the volume of new loans should decline and loan rates should rise relative to market rates when policy is tightened [11]. This behavior they added would indicate loan supply shifts are relatively larger than loan demand shifts. In contrast, most theories of credit rationing suggest that, while the volume of new loans should decline when policy is tightened, bank loan rates should actually increase less than market rates.

Empirical researches have been carried out in the area of modeling a univariate time series using Autoregressive Integrated Moving Average (ARIMA) models popularised by Box and Jenkins (1976). Paul et al used ARIMA model for forecasting average daily share price index of pharmaceutical companies in Bangladesh. In their study, they found the best fitted ARIMA model after considering the different type of factors such as Akaike Information, corrected Akaike information, Schwartz information, mean absolute percent error, root mean square error and absolute mean error. Their empirical results indicated that the ARIMA $(2,1,2)$ model is the best for forecasting the average daily share price indices [9].

Seneviratna and Shuhua, also used univariate time series Autoregressive Integrated Moving Average (ARIMA) model was used to forecast government twelve month Treasury bill rates in Sri Lanka over the period June, 2008 to June, 2013. Box Jenkins methodology was mainly used to build four models and different diagnostic tests and criteria were applied to select the appropriate model. The accuracy of the forecasted values was compared with Mean Squared Error (MSE) and Mean Absolute Error (MAE) and their results revealed that the best ARIMA model for the twelve month treasury bill rates is ARIMA $(1,1,2)[3]$.

Chujai et al conducted a research to find a model for forecasting the electricity consumption in a household. As a main objective of their study, the most suitable forecasting method was fitted. The analysis results suggested that, two forecasting methods called autoregressive integrated moving average and autoregressive moving average (ARMA) are most suitable for forecasting future results. For this purpose they applied Box Jenkins method and identified the best suitable model is ARIMA for monthly and quarterly as forecasting periods. On the other hand, they showed that the ARMA model is suitable for forecasting based on daily and weekly periods [15].

Inflation rate in Nigeria was forecasted by Olajide et al based on the Box Jenkins approach. Yearly data from 1961 to 2010 was used. According to the empirical results, they suggested that the ARIMA $(1,1,1)$ model is the most adequate for the inflation rate. Based on the suggested model, they predicted the inflation rate at $16.27 \%$ in the year 2010 [10].

Okyere and Mensah forecasted inflation rates of Ghana for 2014 base on the Box Jenkins approach. Monthly data from January 2009 to December 2013 was used. According to the results, they suggested that ARIMA $(1,2,1)$ model was appropriate for modelling the inflation rates with a maximum log likelihood value of -64.21, and least AIC value of 13.43, AICc value of 134.87 and BIC value of 140. 61. An ARCH-LM test and Ljung-Box test on theresiduals of the models revealed that the residuals are free from heteroscedasticity and 
serial correlation respectively. Ghana is likely to experience a persistence increase in inflation rate with double digit hence the government should reconsider his monetary policies [4].

Al-Sahib studied the predictability of the Amman Stock Exchange(ASE) based on ARIMA model over a period of seven days. Different diagnostic tests used to perform the best fitted model and showed that the selected model is suitable for forecasting on ASE [13]. Another research based on ARIMA model has done by Nochai et al. They investigated to find a model to forecast three types of oil palm price in Thailand such as Farm price, Wholesale price and Pure oil price. Non-seasonal Box Jenkins methodology is used and three models are found based on the minimum of mean absolute percentage error (MAPE). Finally they developed model for three types of palm oil price and found that models ARIMA $(2,1,0)$ for the farm price, ARIMA $(1,0,1)$ for the wholesale price, and ARIMA $(3,0,0)$ for the pure oil price [13].

Again, Appiah and Adetunde used the Box and Jenkins (1976) approach to model and forecast the exchange rate between the Ghana cedi and the US dollar. In their study, they found that ARIMA $(1,1,1)$ model was appropriate for forecasting, the exchange rate [18].

Logubayom et al presented a study to build a univariate time series models to model the monthly Treasury bill rate of two short term Treasury bills (91 day and 182 day) from the year 1998 to 2012 from the Bank of Ghana using ARIMA models. From the results, it was realized that ARIMA $(3,1,1)$ model was appropriate for modelling the 91-day Treasury bill rate, ARIMA $(1,1,0)$ was the best model for the 182-day Treasury bill rates [7].

Finally, according to literature, another study was carried out by Nasiru and Sarpong employed an empirical approach in modelling and forecasting Inflation in Ghana using the Box-Jenkins approach. The result showed that ARIMA $(3,1,3)(2,1,1)[12]$ model was appropriate for modelling the inflation rates [17].

This study therefore focused on modeling the monetary policy rates of Ghana, to determine an appropriate time series model for predicting these policy rates. The modeling of monetary policy rates will be useful to Central Bank, Commercial Banks, institutions and borrowers. This again will be valuable to the financial markets.

\section{Material And Methods}

This study was carried out in Ghana in April, 2014, using monthly monetary policy rates of Ghana from January 2001 to December 2013. The data was obtained from the website of the Bank of Ghana. The data was modeled using Autoregressive Integrated Moving Average (ARIMA) stochastic model. An autoregressive integrated moving average (ARIMA) model is a generalization of an autoregressive moving average (ARMA) model. These models are fitted to time series data either to better understand the data or to predict future points in the series.

\subsection{Autoregressive Integrated Moving Average (ARIMA) Model}

A time series $Y_{t}$ is said to follow Autoregressive Integrated Moving Average (ARIMA) model if the dth differences $\nabla^{\mathrm{d}} Y_{\mathrm{t}}$ follow a stationary ARMA model. There are three important values which characterize an ARIMA process [8]:

- $\quad \mathrm{p}$, the order of the autoregressive component

- $\mathrm{d}$, the number of differences needed to arrive at a stationary $\operatorname{ARMA}(\mathrm{p}, \mathrm{q})$ process

- $\quad \mathrm{q}$, the order of the moving average component

The general form of the ARIMA (p,d,q) is represented by a backward shift operator as

$$
\emptyset(\mathrm{B})(1-\mathrm{B})^{\mathrm{d}} \mathrm{Y}_{\mathrm{t}}=\theta(\mathrm{B}) \mathrm{e}_{\mathrm{t}},
$$

where the $A R$ and $M A$ characteristic operators are

$$
\begin{aligned}
& \emptyset_{(\mathrm{B})}=\left(1-\emptyset_{1} \mathrm{~B}-\emptyset_{1} \mathrm{~B}^{2}-\ldots-\emptyset_{\mathrm{p}} \mathrm{B}^{\mathrm{d}}\right) \\
& \theta_{(\mathrm{B})}=\left(1-\theta_{1} \mathrm{~B}-\theta_{2} \mathrm{~B}^{2}-\ldots-\theta_{\mathrm{q}} \mathrm{B}^{\mathrm{q}}\right)
\end{aligned}
$$

and

$$
(1-B)^{d} Y_{t}=\nabla^{d} Y_{t}
$$

where

$\emptyset$ is the parameter estimate of the Autogressive component

$\theta$ is the parameter estimate of the Moving Average component

$\nabla$ is the difference

$\mathrm{B}$ is the Backward shift operator

$\mathrm{e}_{\mathrm{t}}$ is a purely a random process with mean zero and $\operatorname{var}\left(\mathrm{e}_{\mathrm{t}}\right)=\sigma_{\mathrm{e}}^{2}$ 
Estimating an ARIMA model was first approached by Box and Jenkins (1976) and according to their methodology, it follows three steps as Identification, Estimation, and Diagnostic Checking. The three steps can be summarized in the following below [8].

\subsection{Model Identification}

Identification step involves the use of the techniques to determine the values of $p, q$ and $d$. The values are determined by using Autocorrelation Function (ACF) and Partial Autocorrelation Function (PACF). For any ARIMA (p, d, q) process, the theoretical PACF has non-zero partial autocorrelations at lags 1, 2, ..., p and has zero partial autocorrelations at all lags, while the theoretical ACF has non zero autocorrelation at lags $1,2, \ldots, \mathrm{q}$ and zero autocorrelations at all lags. The non-zero lags of the sample PACF and ACF are tentatively accepted as the $\mathrm{p}$ and $\mathrm{q}$ parameters. Bad choices of $\mathrm{p}, \mathrm{d}$, and $\mathrm{q}$ lead to bad models, which, in turn, lead to bad predictions (forecasts) of future values [8].

\subsection{Unit Root Test}

Determining whether the time series is stationary or not is a very important concept before making any inferences in time series analysis. Therefore Augmented Dickey Fuller (ADF), Phillips Perron (PP) and Kwiatkowski-Phillips-Schmidt-Shin (KPSS) tests have been used to check the stationarity of the series. The test is based on the assumption that a time series data $y_{t}$ follows a random walk [12]:

$$
\mathrm{Y}_{\mathrm{t}}=\rho \mathrm{y}_{\mathrm{t}-1}+\mathrm{e}_{\mathrm{t}}
$$

Where $\rho$ is the characteristic root of an AR polynomial and $\mathrm{e}_{\mathrm{t}}$ is purely a random process with mean zero and variance $\sigma^{2}$

\subsubsection{Augmented Dickey Fuller (ADF) Test}

Dickey and Fuller (1979) ADF is a test to see if the test can reject non-stationarity. The ADF unit root test, therefore tests [12],

$$
\mathrm{H}_{0}: \rho=1 \text { (non-stationary) }
$$

versus

\subsubsection{Phillips Perron (PP) Test}

$$
\mathrm{H}_{1}: \rho<1 \text { (stationary) }
$$

Phillips and Perron (1988) PP is perhaps the most frequently used alternative to the Augmented Dickey Fuller (ADF) test. It modifies the test statistic so that no additional lags of the dependent variable are needed in the presence of serially-correlated errors. An advantage with the test is that it assumes no functional form for the error process of the variable which means that it is applicable to a very wide set of problems [12].

\subsubsection{Kwiatkowski Phillips Schmidt Sahin (KPSS) Test}

Kwiatkowski et al (1992) KPSS is a test where the null hypothesis is the other way around. It is tests to see if the test can reject stationarity. This is the reverse of PP and ADF test [12].

\subsection{Estimation of Model parameters}

After identifying the possible ARIMA models, the maximum likelihood method is used to estimate the model parameters.

\subsection{Diagnostic Checking}

The next step is to select the best model among all the identified models. For this, residual diagnostics and the model with the maximum log-likelihood and minimum values of Akaike Information Criterion (AIC), modified Akaike Information Criterion (AICc), and Bayesian Information Criterion (BIC) was considered as the best model. Under the residual diagnostics, Ljung-Box Q statistic is used to check whether the residuals are random or not [8].

\subsubsection{Akaike Information Criterion (AIC)}

The Akaike's Information Criterion (AIC) says to select the ARIMA(p,d,q) model which minimizes [8],

$$
\mathrm{AIC}=-2 \ln \mathrm{L}+2 \mathrm{k}
$$

where $\ln L$ is the natural logarithm of the estimated likelihood function and $\mathrm{k}=\mathrm{p}+\mathrm{q}$ is the number of parameters in the model. The AIC is an estimator of the expected Kullback-Leibler divergence, which measures the closeness of a candidate model to the truth. The smaller this divergence, the better the model [8].

A problem arises in that AIC is a biased estimator of the expected KL divergence in ARMA(p,d,q) models [8]. An alternative AIC statistic which corrects for this bias is 


\subsubsection{Bayesian Information Criterion (BIC)}

$$
\mathrm{AICC}=\mathrm{AIC}+\frac{2(K+1)(K+2)}{n-k-2}
$$

The Bayesian Information Criterion (BIC) says to select the ARIMA(p,d,q) model which minimizes [8],

$$
\mathrm{BIC}=-2 \ln \mathrm{L}+2 \mathrm{k} \ln (\mathrm{n}) \text {; }
$$

where $\operatorname{lnL}$ is the natural logarithm of the estimated likelihood function and $\mathrm{k}=\mathrm{p}+\mathrm{q}$ is the number of parameters in the model and $\mathrm{n}$ is total observations.

Both AIC and BIC require the maximization of the log likelihood function and When we compared AICC to BIC offers a stiffer penalty for overparameterized models [8].

An overall check of the model adequacy was made using the modified Box-Pierce $\mathbf{Q}$ statistics. The test statistics is given by:

$$
Q_{m}=n(n+2) \sum_{k=1}^{n}(n-k)^{-1} r_{k}^{2} \approx \chi_{m-r}^{2}
$$

where:

$r_{k}^{2}=$ the residuals autocorrelation at lag $k$

$n=$ the number of residual

$m=$ the number of time lags included in the test.

When the p-value associated with the $\mathbf{Q}$ is large the model is considered adequate, else the whole estimation process has to start again in order to get the most adequate model. Here all the tests were performed at the $95 \%$ confidence interval [8].

Furthermore, a plot of the ACF squared residual and PACF squared residuals was performed on the residuals of the fitted model to check for heteroscedasticity and again an ARCH LM-test for conformity of the presence of, or otherwise ARCH effect was performed.

\subsection{Stationarity}

\section{Results And Discussion}

A behavioral analysis was carried out on the time series plot and correlogram (ACF plot) and partial correlogram (PACF plot). The time series plot of fig.1 shows monetary policy rates (MPR) of Ghana from January 2001 to December 2013 and it reveals an existence non-significant trend. The ACF plot of Fig.1 shows the strong and slowly decaying autocorrelations with a significant spike at lag 1 of PACF plot of Fig.1. This implies that the data non-stationarity.

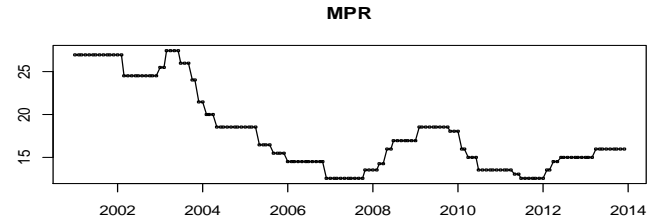

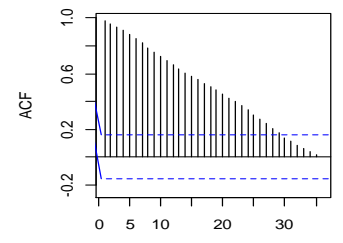

Lag

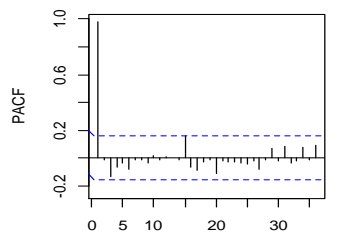

Lag

Figure 1: Time series plot and ACF and PACF plot

Table 1: Unit Root Tests Results

\begin{tabular}{|llll|}
\hline Tests & Order of Difference & Test Statistic & P-Value \\
\hline ADF & 0 & -2.0059 & 0.5739 \\
\hline PP & 0 & -3.4367 & 0.9137 \\
\hline KPSS & 0 & 3.4107 & 0.0100 \\
\hline & & & \\
\hline ADF & 1 & -3.8776 & 0.0171 \\
\hline PP & 1 & -195.6381 & 0.0100 \\
\hline KPSS & 1 & 0.3474 & 0.0998 \\
\hline
\end{tabular}


The ADF, PP and KPSS test further confirm the non-stationarity of the series in Table 1 but the series attain it stationarity at the first difference as shown again in Table 1 . Remember that KPSS is the reverse of $\mathrm{ADF}$ and PP.

Fig.2 shows the Time series plot and ACF and PACF plot of the first difference of the series. Clearly, the correlogram tail off at lag 2 , confirming stationarity. We also saw a significant spike at lag and others were not significant.
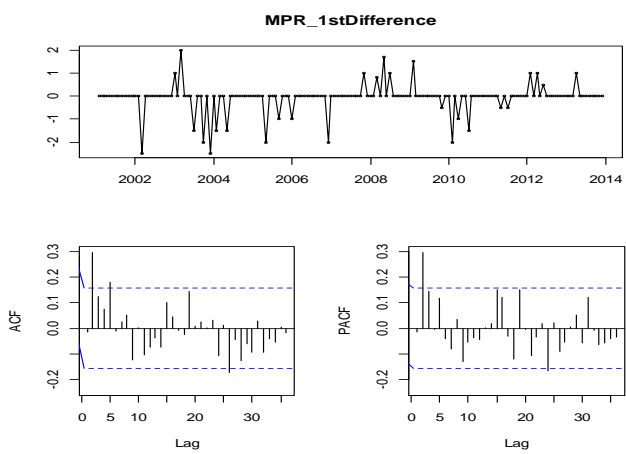

Figure 2: Time series plot and ACF and PACF plot of 1st Difference

\subsection{Model Identification}

From the results of fig. 2 and the unit root results of Table 1, which revealed that the data is stationary at the first difference, we can propose the moving average (q) component and autogressive (p) component with the significant spike to form our ARIMA model based on the ACF and PACF plot in fig.2. The autocorrelation (ACF) plot in Fig. 2 shows a spike from lag 2 to lag 5, indicating a moving average component need to be added to the model and Partial autocorrelation (PACF) plot in the same Fig.2 shows a spike in lag 2, also indicating an autoregressive component need to be added to de model. Therefore, two models were suggested from both ACF and PACF plots of Fig.2. They are $\operatorname{ARIMA}(2,1,2)$ and $\operatorname{ARIMA}(2,1,5)$ and through Box-Jenkins approach, the two models were examined and $\operatorname{ARIMA}(2,1,2)$ was selected as the best but it model parameters estimate were all not significant, hence the process starts again by identifying different tentative models abiding by the principle of parsimony but Table 2 shows the parameters estimate of $\operatorname{ARIMA}(2,1,2)$.

Table 2: Model Parameters Estimates of ARIMA(2,1,2)

\begin{tabular}{|lllll|} 
Component & Coefficient & S.E & Test Statistic & P-Value \\
\hline Constant & -0.0239 & 0.0279 & -0.86 & 0.393 \\
\hline AR(1) & 0.3941 & 0.2719 & 1.45 & 0.149 \\
\hline AR(1) & 0.2607 & 0.2655 & 0.98 & 0.328 \\
\hline MA(1) & 0.4501 & 0.2804 & 1.61 & 0.111 \\
\hline MA(2) & -0.0478 & 0.2666 & -0.18 & 0.858 \\
\hline
\end{tabular}

Table 3: Different ARIMA(p,1,q) Model Fitted

\begin{tabular}{|lllll|}
\hline Model & AIC & AICC & BIC & Log-Likelihood \\
\hline ARIMA(0,1,0) & 287.57 & 287.60 & 290.62 & -142.79 \\
\hline ARIMA(0,1,1) & 289.57 & 289.65 & 295.66 & -142.79 \\
\hline ARIMA(1,1,1) & 291.57 & 291.73 & 300.70 & -142.79 \\
\hline ARIMA(2,1,1) & $274.98^{*}$ & $275.25^{*}$ & $287.16^{*}$ & $-133.49^{*}$ \\
\hline ARIMA(1,1,2) & 275.99 & 276.26 & 287.17 & -134.00 \\
\hline ARIMA(1,1,3) & 277.33 & 277.74 & 288.17 & -133.67 \\
\hline ARIMA(3,1,1) & 276.92 & 277.32 & 292.55 & -133.46 \\
\hline ARIMA(2,1,3) & 278.92 & 279.49 & 292.14 & -133.46 \\
\hline
\end{tabular}

*Best based on model selection criterion

From Table 3, ARIMA $(2,1,1)$ was the best model based on the selection criterion used. This is because it satisfies the entire selection criterion. The parameters of this model were then estimated.

\subsection{Model Estimation}

Maximum likelihood is used to estimate the model parameters. As shown in Table 4 below show that $\mathrm{AR}(2)$ was strongly significant with rest not significant. 
Table 4: Model Parameters Estimate for $\operatorname{ARIMA}(2,1,1)$

\begin{tabular}{|l|llll|}
\hline Component & Coefficient & S.E & Test Statistic & P-Value \\
\hline Constant & -0.0234 & 0.0275 & -0.85 & 0.396 \\
\hline AR(1) & 0.3557 & 0.2031 & 1.75 & 0.082 \\
\hline AR(2) & 0.3059 & 0.0813 & 3.76 & 0.000 \\
\hline MA(1) & 0.4089 & 0.2104 & 1.94 & 0.054 \\
\hline
\end{tabular}

\subsection{Model Diagnostic}

In addition, the model was diagnosed to see how well it fits the data. It can be seen from Fig. 3 that the ACF of the residuals shows that the residuals are white noise although there was a significant spike at lag 0 of the ACF which could be due to random factor. Furthermore, the plot of the Ljung-Box p-values in Fig. 3 shows that the model was adequate for representing the data as they were above the 0.05 value indicated by the blue line.
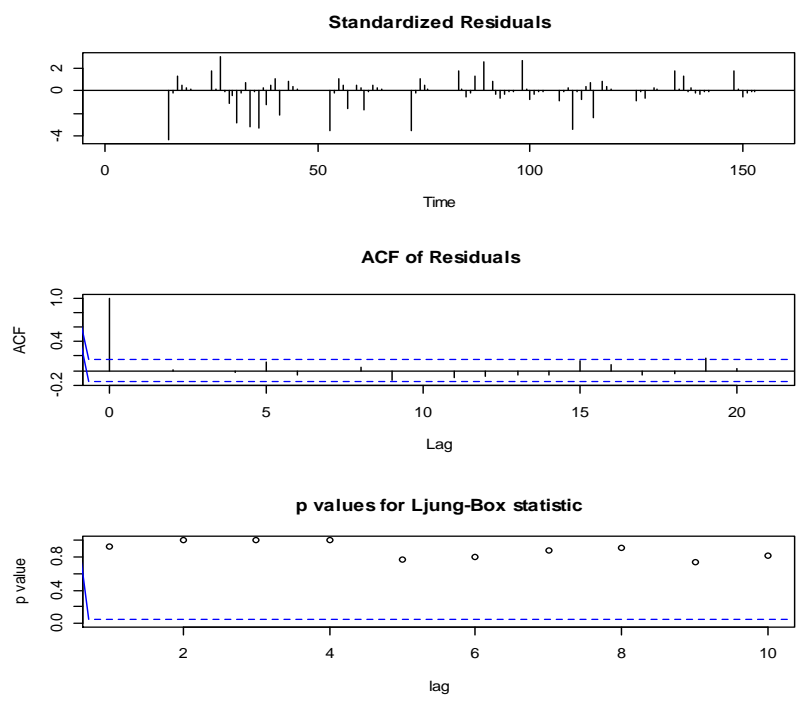

Figure 3: Diagnostic plot of residuals of $\operatorname{ARIMA}(2,1,1)$

Also, The ACF plot of Squared of Residuals, PACF plot of Squared of Residuals in Fig.4 and an ARCH-LM test in Table 5 showed that there were no ARCH effects; hence the residuals have a constant variance. The Ljung-Box p-values (> 0.05) in Fig.3 showed that there is no serial correlation in the residuals of the model. The ACF plot of the residuals in Fig.3 also shows that the residuals are white noise series.

Table 5: Diagnostic Test Statistic

\begin{tabular}{|lll}
\hline Test & Statistic & P-Value \\
\hline ARCH LM & 7.819 & 0.7991 \\
\hline
\end{tabular}
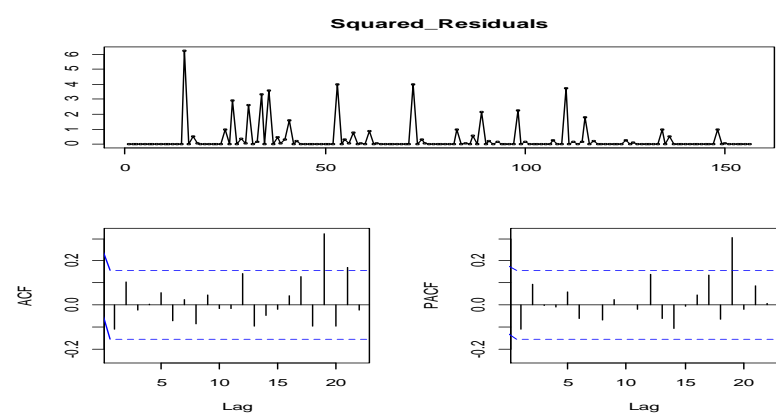

\section{Conclusion}

This study used time series to model the monetary policy rate of Ghana using data from the Bank of Ghana (BoG) from January 2001 to December, 2013. The modeling of the monetary policy rate was done mainly by ARIMA model. The Study revealed that the monetary policy rate is best modeled with 
ARIMA(2,1,1). The diagnostics of this models showed that the model is adequately fits the series hence is adequate for the forecasting of monetary policy rates in Ghana.

\section{References}

[1]. Bank of Ghana, Bank Monetary Policy rate, http://www.bog.gov.gh/, (accessed on April 1, 2014).

[2]. B.S. Bernanke and A. S. Blinder, The Federal Funds Rate and the Channels of Monetary Transmission, American Economic Review, 1992, 901-21.

[3]. D.M.K.N. Seneviratna and Mao Shuhua, Forecasting the Twelve Month Treasury Bill Rates in Sri Lanka: Box Jenkins Approach, IOSR Journal of Economics and Finance (IOSR-JEF) 1(1), 2013, 44 - 47.

[4]. F. Okyere and C. Mensah, Empirical Modelling and Model Selection for Forecasting Monthly Inflation of Ghana. Mathematical Theory and Modeling, 4(3), 2014, 99-106.

[5]. M. Gertler and S. Gilchrist, The Role of Credit Market Imperfections in the Monetary Transmission Mechanism: Arguments and Evidence, Scandinavian Journal of Economics, 95(1), 1993, 43-64.

[6]. M. Gertler and S. Gilchrist, Monetary Policy, Business Cycles, and the Behaviour of Small Manufacturing Firms, Quarterly Journal of Economics, May, 1994, 309-40.

[7]. I. A. Logubayom, S. Nasiru and A. Luguterah, Modelling the Rate of Treasury Bills in Ghana, Mathematical Theory and Modeling, 3(4), 2013, 102-108.

[8]. J. M. Tebbs, STAT 520 Forecasting and Time Series (University of South Carolina, Department of Statistics, spring, 2010).

[9]. J.C. Paul, S. Hoque, and M.M. Rahman, Selection of Best ARIMA Model for Forecasting Average Daily Share Price Index of Pharmaceutical Companies in Bangladesh: A case Study on Square Pharmaceutical Ltd, Global Journal of Management and Business Research, 13(3), 2013.

[10]. J.T. Olajide, O.A. Ayansola, M.T. Odusina, and I.F. Oyenuga, Forecasting the Inflation Rate in Nigeria: Box Jenkins Approach, IOSR Journal of Mathematics (IOSR-JM), 3(5), 2012, 15-19.

[11]. A. K. Kashyap and J. C. Stein, What do a million observations on banks say about the transmission of monetary policy? American Economic Review, 90(3), 2000, 407-428.

[12]. L. Mahadeva and P. Robinson, Unit root testing to help model building (centre for central Bank Studies, Bank of England, 2004)

[13]. M. Al-Shiab, The Predictability of the Amman Stock Exchange using the Univariate Autoregressive Integrated Moving Average (ARIMA) Model, Journal of Economic \& Administrative Sciences, 22(2), 2006

[14]. Moneatry Policy, Meaning and Objectives of Monetary Policy, http://www.preservearticles.com, (accessed on April 1, 2014).

[15]. P. Chujai, N. Kerdprasop, and K. Kerdprasop, Time Series Analysis of Household Electric Consumption with ARIMA and ARMA Models, Proc. IMECS Conf., Hong Kong, 2013.

[16]. R. Nochai, and T. Nochai, ARIMA Model for Forecasting Oil Palm Price, Proc. 2nd IMT-GT Regional Conf. on Mathematics, Statistics and Applications, University Sains Malaysia, Penang, 2006.

[17]. S. Nasiru and S. Sarpong, Empirical Approach to Modelling and Forecasting Inflation in Ghana, Current Research Journal of Economics Theory, 4(3), 2012, 83-87.

[18]. S.T. Appiah and I.A. Adetunde, Forecasting exchange rate between the Ghana cedi and the US dollar using time series analysis. Current Research Journal of Economics Theory, 3(2), 2011, 76-83. 